\title{
Aplikasi Media Komunikasi Bagi Penyandang Disabilitas Berbasis Android
}

\author{
Saprina Mamase ${ }^{1}$ \\ Teknik Informatika \\ Politeknik Gorontalo \\ rina@poligon.ac.id
}

\author{
Ismail Mohidin ${ }^{2}$ \\ Teknik Informatika \\ Politeknik Gorontalo \\ is.mohidin@poligon.ac.id
}

\author{
Muh. Fadli Hulopi ${ }^{3}$ \\ Teknik Informatika \\ Politeknik Gorontalo \\ fadli.mhs15@ti.poligon.ac.id
}

\begin{abstract}
Kesulitan yang dirasakan oleh penyandang disabilitas tunarungu dalam berkomunikasi antara lain lawan bicara yang tidak mengerti bahasa isyarat dan lawan berbicara seorang tunanetra. Begitupun yang dirasakan oleh tunanetra yang kesulitan berkomunikasi langsung dengan tunarungu, bila diantaranya diharuskan untuk berkomunikasi pasti memerlukan perantara atau orang ketiga. Kesulitan berkomunikasi jarak jauh pun dirasakan oleh tunarungu dan tunanetra, tunarungu yang biasa menggunakan aplikasi chatting/messaging atau video call secara langsung, sedangkan tunanetra yang menggunakan fitur telepon/voice call langsung. Maka diperlukan aplikasi yang dapat dipakai oleh keduanya. Penelitian ini mengusulkan aplikasi media komunikasi bagi penyandang disabilitas berbasis Android untuk tunarungu dan tunanetra dalam berkomunikasi. Karena bersifat mobile, penulis berharap dengan adanya aplikasi ini, tunarungu dan tunanetra dapat terbantu dalam berkomunikasi jarak jauh.
\end{abstract}

Kata kunci : Media komunikasi, aplikasi Android, tunarungu, tunanetra

\section{PENDAHULUAN}

Komunikasi merupakan suatu proses sosial yang sangat mendasar dalam kehidupan manusia. Karena setiap masyarakat (manusia), baik yang primitif maupun yang modern, berkeinginan mempertahankan suatu persetujuan mengenai berbagai aturan sosial melalui komunikasi. Melalui proses komunikasi, manusia juga mampu mempelajari banyak hal yang dapat memperluas wawasannya. Manusia mampu mengenali serta memahami sesamanya, lingkungan sekitarnya atau bahkan lingkungan yang belum pernah dilihatnya sekalipun melalui proses komunikasi.

Smartphone merupakan salah satu teknologi komunikasi yang cukup populer saat ini. smartphone saat ini menjadi alat komunikasi dan asisten pribadi yang sangat penting. Bentuknya yang portabel dan mudah dibawa membuat orang menyukainya sebagai alat utama dalam kehidupan sehari-hari. Berbagai macam aplikasi tersedia di smartphone, baik yang memiliki antarmuka grafis maupun dengan antarmuka berbasis suara. Smartphone berusaha agar orang bisa senyaman mungkin menggunakanya.
Namun, komunikasi antara penyandang disabilitas saat ini yang menjadi sedikit sulit. Khususnya penyandang tunarungu dan tunanetra. Secara langsung mereka memiliki kesulitan dalam berkomunikasi, perlu orang ketiga untuk menghubungkan mereka bila akan berkomunikasi. Sehingga komunikasi yang terjadi kurang efektif. Penyandang tunanetra merupakan kategori disabilitas yang memiliki keterbatasan fisik untuk melakukan pekerjaan yang memerlukan kemampuan visualisasi. Misalnya, untuk membaca teks penyandang tunanetra memerlukan bantuan system Braille ataupun sistem penghasil suara digital. Dalam berkomunikasi, tunanetra mengandalkan suara dan pendengaran. Sedangkan penyandang tunarungu merupakan kelainan fisik yang dialami individu berupa ketidakmampuan mendengar secara normal, hal ini disebabkan penyandang tunarungu memiliki gangguan komunikasi secara lisan dengan orang-orang disekitarnya sehingga untuk mengatasinya penyandang tunarungu memanfaatkan gerakan tangan atau bahasa isyarat yang harus dilihat oleh lawan bicaranya untuk berkomunikasi.

Keterbatasan tersebut tentunya menciptakan sedikit masalah bagi penyandang disabilitas tunanetra dan tunarungu dalam berkomunikasi. Untuk dapat mendukung proses komuikasi jarak jauh yang lebih efektif bagi penyandang disabilitas tunarungu dan tunanetra, maka penulis mengusulkan suatu media komunikasi sehingga akan membantu penyandang disabilitas tunarungu, tunanetra dan masyarakat normal dalam berkomunikasi.

\section{METODOLOGI}

Gambaran Umum Sistem

Gambaran umum dari sistem yang diusulkan akan di ilustrasikan pada Gambar 1. Berikut adalah penjelasan terkait pada Gambar 1 .

1. Pengguna tunanetra menjalankan fungsi Speech Recognition, sistem akan menampilkan dialog Voice Input sesuai dengan suara yang di inputkan (Indonesian). Setelah dialog Voice Input tampil, saat itulah pengguna mulai berbicara.

2. Suara tersebut akan dikirim ke server Google Speech Recognition secara realtime untuk di konversi menjadi teks.

3. Google Speech Recognition mengkonversi suara kedalam bentuk teks dengan cara membandingkan data 
suara yang diterima dengan database yang dimiliki Google. Setelah dilakukan konversi, Google Speech Recognition mengirim teks hasil konversi.

4. Ketika pengguna tunanetra menjalankan fungsi Chatting, teks yang diterima device dari Google Speech Recognition dikirim ke system (chatting), kemudian text tersebut dikirim ke pengguna tunarungu.

5. Pengguna tunarungu menerima inbox dalam bentuk text.

6. Ketika pengguna tunarungu menjalankan fungsi Text To Speech, teks tersebut dikirim ke server Google Text To Speech, untuk dikonversi menjadi suara/ucapan.

7. Google Text To Speech akan memproses/mengkonversi teks menjadi suara/ucapan. Setelah dilakukan konversi, Google Text To Speech memutar/menjalankan suara (ucapan) secara realtime ke device, selain itu device akan membuat file suara ke dalam format .mp3.

8. Ketika pengguna tunarungu menjalankan fungsi Chatting, suara yang diterima device dari Google Text To Speech dikirim ke system (chatting), kemudian suara/ucapan tersebut dikirim ke pengguna tunanetra.

9. Pengguna tunanetra menerima inbox dalam bentuk suara/ucapan.

10. Untuk pengguna normal, dapat mengjalankan kedua fungsi dari Google.

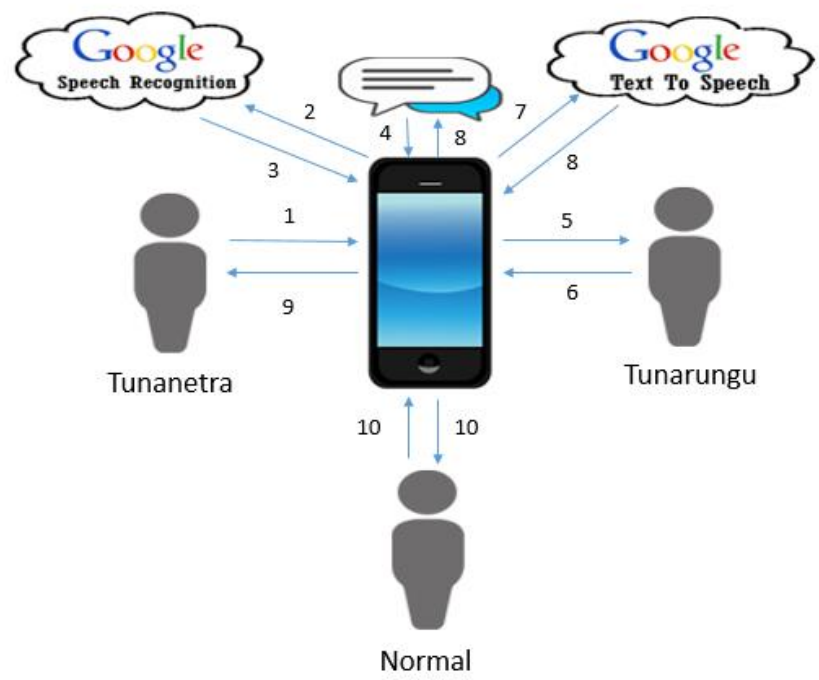

Gambar 1 Desain Sistem yang Diusulkan

\section{Use Case Diagram}

Use Case Diagram mendeskripsikan sebuah interaksi antar satu atau lebih aktor dengan sistem yang akan dibuat. Secara kasar use case digunakan untuk mengetahui fungsi apa saja yang ada di dalam sebuah sistem dan siapa saja yang berhak menggunakan fungsi-fungsi tersebut.

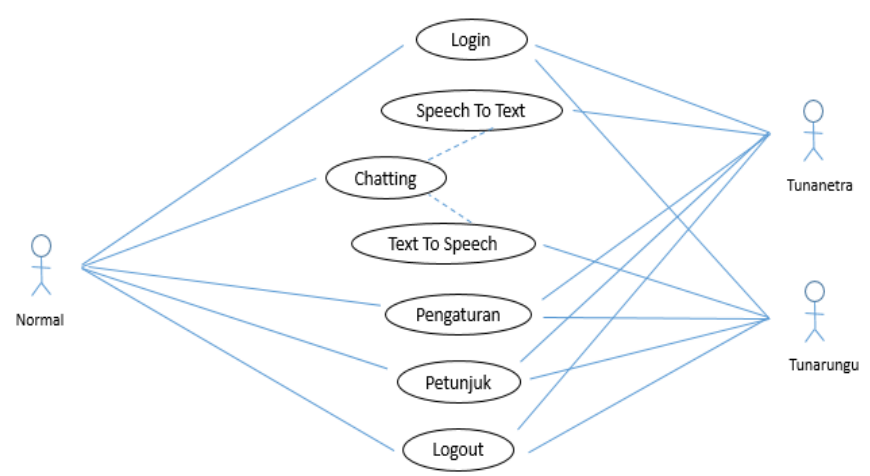

Gambar 2 Use Case Diagram yang Diusulkan

Keterangan :

Normal : Pengguna yang dapat menggunakan semua fitur yang tersedia pada sistem

Tunarungu : Sebagai pengguna yang dapat menggakses fitur Text To Speech pada system

Tunanetra : Sebagai pengguna yang dapat menggakses fitur Speech Recognition pada system

\section{Sequence Diagram}

Sequence diagram adalah suatu diagram yang menggambarkan interaksi antar objek dan mengindikasikan komunikasi diantara objek-objek tersebut. Diagram ini juga menunjukkan serangkaian pesan yang dipertukarkan oleh objek-objek yang melakukan suatu tugas atau aksi tertentu. Objek-objek tersebut kemudian diurutkan dari kiri ke kanan, aktor yang menginisiasi interaksi biasanya ditaruh di paling kiri dari diagram.

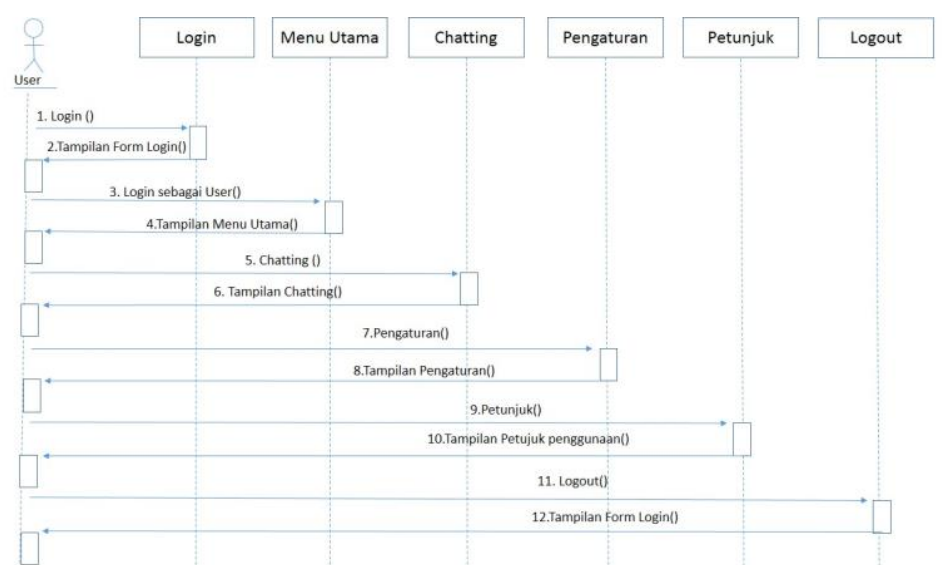

Gambar 3. Sequence Diagram User 
Tabel 1. Deskripsi Sequence Diagram User

\begin{tabular}{|l|l|}
\hline Nama Sequence & Fungsi Sequence \\
\hline User & $\begin{array}{l}\text { User disini adalah pengguna yang } \\
\text { terdiri dari Tunanetra, Tunarungu } \\
\text { dan user normal }\end{array}$ \\
\hline Login & Masuk sebagai User \\
\hline Menu Utama & $\begin{array}{l}\text { Di menu utama kita dapat } \\
\text { mengakses beberapa fitur yaitu } \\
\text { Chatting, pengaturan, petunjuk } \\
\text { penggunaan. }\end{array}$ \\
\hline Chatting & $\begin{array}{l}\text { Chatting adalah proses komunikasi } \\
\text { Antara pengguna aplikasi }\end{array}$ \\
\hline Pengaturan & $\begin{array}{l}\text { Pengaturan adalah menseting dari } \\
\text { aplikasi }\end{array}$ \\
\hline Petunjuk & $\begin{array}{l}\text { Petunjuk yaitu berupa petunjuk } \\
\text { penggunaan aplikasi }\end{array}$ \\
\hline Logout & $\begin{array}{l}\text { Logout adalah menu untuk keluar } \\
\text { dari aplikasi }\end{array}$ \\
\hline
\end{tabular}

\section{HASIL DAN PEMBAHASAN}

\section{Perancangan Antarmuka}

Perancangan antarmuka bertujuan untuk memberikan gambaran tentang aplikasi yang akan dibangun, sehingga mempermudah dalam mengimplementasikan aplikasi serta memudahkan dalam pembuatan aplikasi.

1. Perancangan Tampilan Login

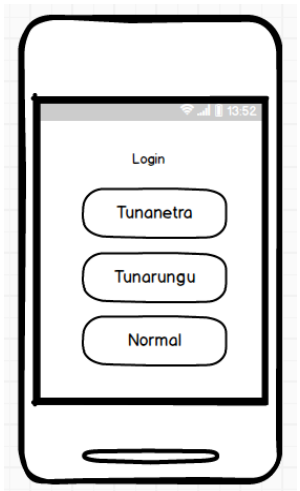

Gambar 4. Perancangan Tampilan Login

Perancangan tampilan login terdapat 3 fitur yaitu tunanetra, tunarungu dan normal. Ketika memilih fitur Tunanetra maka akan masuk pada tampilan khusus Tunanetra.begitu pula Tunarungu. Untuk fitur normal, didalamnya terdapat 2 pilihan fitur yang berbeda, yaitu text to speech, dan speech recognition.

2. Perancangan Tampilan untuk User Normal

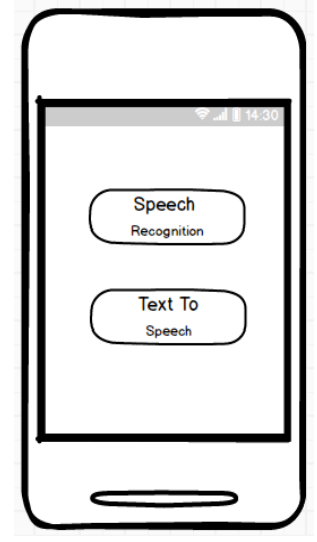

Gambar 5. Perancangan Tampilan dua pilihan untuk user Normal

Pada tampilan untuk orang normal terdapat 2 pilihan fitur yaitu speech recognition dan text to speech.

3. Perancangan Tampilan Menu

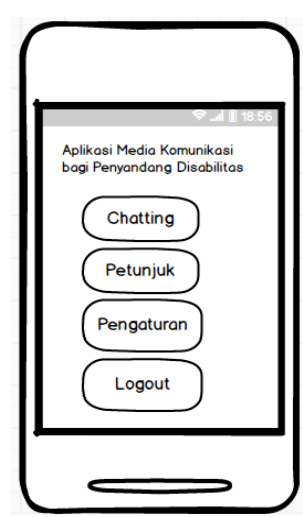

Gambar 6. Perancangan Tampilan Menu

Pada menu utama kita bisa lihat terdapat beberapa button yaitu chatting, petunjuk, pengaturan, Logout.

4. Perancangan Tampilan Chating

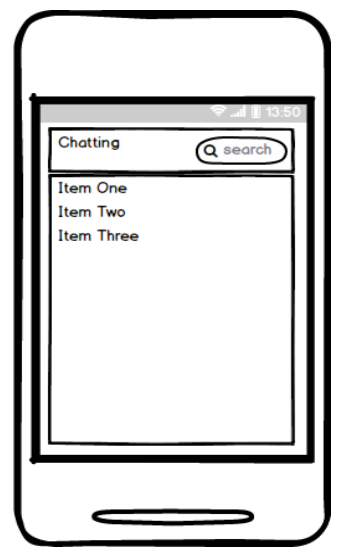

Gambar 7. Perancangan Tampilan Chatting 
Pada menu chating kita dapat melihat list view, yang mana lisview ini adalah teman dari si pengguna.

5. Perancangan antarmuka untuk Tunanetra (Speech Recognition)

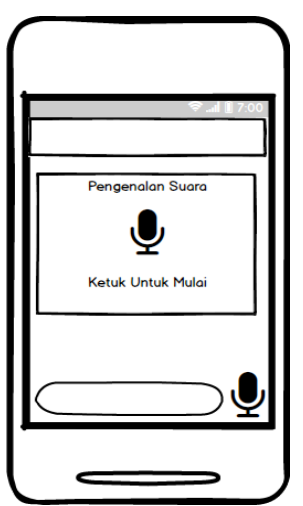

Gambar 8. Perancangan Antarmuka untuk Tunanetra(1)

Pada perancangan antar muka untuk tunanetra kita bisa lihat, terdapat fitur pengenalah suara. Ketika kita ketuk untuk mulai, kita akan masuk pada fitur berikutnya yaitu mendengarkan.

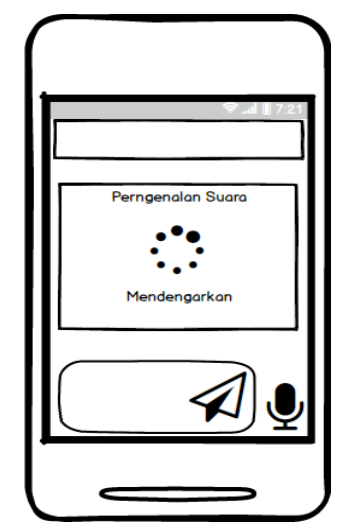

Gambar 9. Perancangan Antarmuka untuk Tunanetra(2)

Pada fitur ini, pengguna akan mengimputkan suara, kemudian suara akan dikonversi ke text dan text tersebut akan di kirim ke pangguna tunarungu.

6. Perancangan antarmuka untuk Tunarungu ( Text to
Speech)

Pada fitur ini pangguna akan mengimputkan text kemudian text tersebut di konversi ke bentuk suara, dan suara tersebut akan direkam oleh system, lalu di kirim ke pengguna tunanetra.

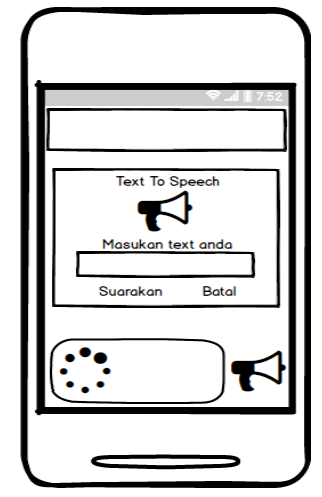

Gambar 10. Perancangan antarmuka untuk Tunarungu

\section{KESIMPULAN}

Aplikasi Media Komunikasi Bagi Penyandang Disabilitas Berbasis Android akan diimplementasikan di Sekolah Luar Biasa yang ada di Kota Gorontalo. Aplikasi ini diharapkan dapat mendukung proses komunikasi yang lebih efektif antara penyandang disabilitas tunarungu dan tunanetra.

Manfaatnya adalah untuk mempermudah penyandang disabilitas tunarungu dan tunanetra untuk saling bertukar informasi.

\section{SARAN}

Aplikasi Media Komunikasi Bagi Penyandang Disabilitas Berbasis Android dapat dikembangkan lagi dengan penambahan fitur-fitur yang dapat mendukung sistem agar sesuai dengan kebutuhan yang ada.

Kajian terkait penelitian ini akan berlanjut hingga ke tahap implementasi dan pengujian pada sistem yang diusulkan.

\section{DAFTAR PUSTAKA}

Garibay, F. R., Olivarria, C. M., Aguilera, A. F. E. \& Huegel, J. C., (2014). MyVox -Device For The Communication Between People: Blind, Deaf, Deaf-Blind And Unimpaired.IEEE Global Humanitarian Technology Conference (GHTC 2014), 10-13 October, San Jose, CA, USA, 506-509.

Haviluddin (2011) 'Memahami Penggunaan UML ( Unified Modelling Language )', Memahami Penggunaan UML (Unified Modelling Language), 6(1), pp. 1-15. doi: 10.1017/CBO9781107415324.004.

Justicia, L. T., Tolle, H. and Amalia, F. (2017) 'Rancang 
Bangun Aplikasi Messaging Berbasis Voice Interaction

Bagi Penderita Tunanetra Pada Sistem Operasi Android', 1(7), pp. 620-627.

Tasmawati, M. (2012) 'Aplikasi Konversi Regular Grammar Menjadi Ekspresi Regular dengan Menggunakan Bahasa Pemrogramman Java', Skripsi Program Studi Teknik Informatika, pp. 4-6. Liga, W. and Fernando, E. (2017) 'Perancangan Aplikasi Komunikasi Penyandang Tunarungu Berbasis Android', 12(1), pp. 984-996. 